\title{
Correction to: Antenatal Management for Women with Inflammatory Bowel Disease: Experience from Our 'IBD MOM' Clinic
}

\author{
Ariella Bar-Gil Shitrit ${ }^{1} \cdot$ Yael Cohen ${ }^{2} \cdot$ Ori Hassin $^{3} \cdot$ Ami Ben Ya'acov $^{1} \cdot$ Rivkah Farkash $^{2} \cdot$ Benjamin Koslowsky $^{1}$. \\ Yael Milgrom ${ }^{1} \cdot$ Dan Meir Livovsky ${ }^{1}$. Arnon Samueloff ${ }^{2} \cdot$ Eran Goldin $^{1} \cdot$ Sorina Grisaru-Granovsky ${ }^{2}$
}

Published online: 27 April 2018

○) Springer Science+Business Media, LLC, part of Springer Nature 2018

\section{Correction to: Digestive Diseases and Sciences https://doi.org/10.1007/s10620-018-5048-x}

The original version of the article unfortunately contained tagging error in first and family name of authors Ariella BarGil Shitrit and Ami Ben Ya'acov. This has been corrected with this erratum.

Ariella Bar-Gil Shitrit—Ariella—first name; Bar-Gil Shitrit-family name.

Ami Ben Ya'acov-Ami-first name; Ben Ya'acovfamily name.

The original article can be found online at https://doi.org/10.1007/ s10620-018-5048-x.

Ariella Bar-Gil Shitrit ariellash@szmc.org.il

1 IBD MOM Unit, Digestive Diseases Institute, Shaare Zedek Medical Center, Affiliated with the Medical School, Hebrew University, Jerusalem, Israel

2 Department of Obstetrics and Gynecology, Shaare Zedek Medical Center, Affiliated with the Medical School, Hebrew University, Jerusalem, Israel

3 Medical School, Ben Gurion University of the Negev, Beer Sheva, Israel 